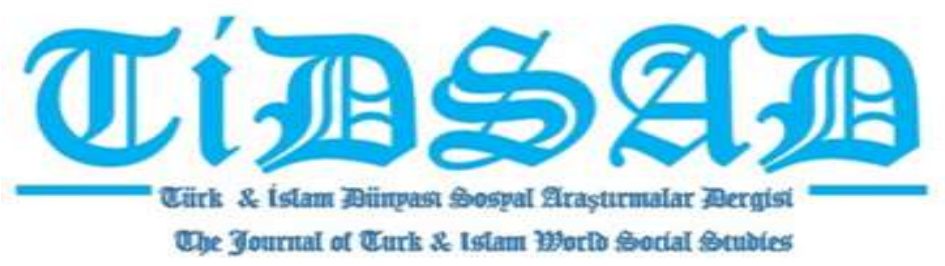

Yıl: 6, Sayı: 23, Aralık 2019, s. 197-206

Tekin İŞLEK

İstanbul Aydın Üniversitesi Yüksek Lisans Öğrencisi, tekin.islek@hotmail.com

\title{
İSTANBUL (KADIKÖY) İLÇESİ YEREL YÖNETIM UYGULAMALARININ KATILIMCI DEMOKRASİ AÇISINDAN \\ TARTIŞILMASI
}

Özet

Yerel yönetimler kamu hizmeti alanlara en yakın birim olduklarından halkın yönetime katılımı, yerel ölçekte daha kolay ve etkin gerçekleşebilmektedir. Nitekim halkın bilgi sahibi olması ve kendilerini ilgilendiren konularda görüş, eleştiri ve projelerini yöneticilere iletebilmesi açısından önem taşıyan belediyelerde, kent konseyi, gençlik, kadın, çocuk, kıdemli yurttaş, engelli meclisleri gibi kurumlar aracılığıyla yönetime dâhil olması günümüzde katılımcı demokrasi uygulamalarının etkili olarak kullanıldığını göstermektedir. Bu nedenle çalışmada, Kadıköy Belediyesi'nde, İlçe'nin sorunlarının tespiti ve çözümünde kent ortaklarıyla birlikte hareket edebilmek anlayışı ile kullanılan katılımcı demokrasi uygulamaları değerlendirilmiştir.

Anahtar Kelimeler: Yerel Yönetim, Kamu Hizmeti, Belediye, Demokrasi, Kat1lim.

\section{ISTANBUL (KADIKOY) DISTRICT LOCAL GOVERNMENT PRACTICES GUIDE DEMOCRACY OPENING DISCUSSION}

\section{Summary}

Since local administrations are the closest units to public service recipients, public participation in the administration can be realized more easily and effectively at the local scale. As a matter of fact, in the municipalities which are important for the public to have information and to convey their opinions, criticisms and projects to the managers on the issues that concern them, the participation of the government through institutions such as city council, youth, women, children, senior citizens 
and disabled councils shows that participatory democracy practices are being used effectively today. In this study, In Kadikoy Municipality, which was selected as a sample subject, participatory democracy practices used to identify and solve the problems of the district were evaluated.

Key Words: Local Government, Public Service, Municipality, Democracy, Participation.

\section{Giriş}

Belediyeler, bireylerin ilçede birlikte yaşam sürmeleri neticesinde oluşan ihtiyaçların karşılanabilmesi amaciyla meydana getirilen yerel yönetim birimleri olup merkezi yönetimin yetkilerinin yerelde kullanılarak, hizmetin daha hızlı, etkin ve verimli sunulmasını sağlayan önemli yerel makamlardır. Yerel ihtiyaçlar bu sayede daha çabuk ve halkın da yönetimde söz sahibi olduğu eşit imkânlarda karşılanmaktadır. Dolayısıyla belediyeler halkın yönetime katılmasına önem vermekte ve birimlerini buna göre meydana getirmektedir.

Bununla birlikte yerel demokrasinin de en iyi işlediği yerler olan belediyelerin işlevleri, tarihsel süreçle birlikte halkın siyasi, idari, politik, teknolojik, sosyo-kültürel, ekonomik tercih ve değişimine bağlı olarak sürekli değişikliğe uğramıştır. Bu nedenle çalışmada, belediyeler düzeyinde katılımcı demokrasi uygulamaları ele alınmış, İstanbul ili Kadıköy ilçesi belediye çalışmaları katılımcı demokrasi açısından değerlendirilmiştir.

\section{Katılımın Kavramı ve Demokratik Nitelikleri}

Siyaset biliminin bir kavramı olan "katılım" kavramı bireyin kendi ile ilgili konularda izleyici durumundan daha aktif bir konuma gelerek çevresel, siyasal, fiziksel ve daha başka düzeylerde yönetimde söz sahibi olması ve işbirliğine gitmesidir (Kaypak, 2012: 174). Başka bir deyişle katılım; vatandaşların devlet düzeyinde verilen kararları etkileyebilmesi, çevre planlamaları ve programlar konusunda daha etkin bir rol üstlenmesi ile ideal demokratik düzenleri hazırlayan bir kavram olarak ifade edilebilir.

Demokrasinin yüzyıllar süren gelişimi incelendiğinde katılımın demokratik devletlerde vazgeçilmez bir unsur olduğu görülmektedir. İlk başlarda doğrudan vatandaşın devlet işlerine dahil olduğu ve katılımın bu şekilde gerçekleştiği yapılan çalışmalarda ifade edilmektedir. Ancak küreselleşme olgusu, artan nüfus ve siyasi tarihin değişken yapısı doğrudan demokrasilerin yerini temsili demokrasi uygulamalarına bırakmıştır. $\mathrm{Bu}$ durum ise katılım kavramının temsili demokrasilerde güçlendirilmesi gereğini ortaya çıkarmıştır. Zira temsili demokraside katılım güçlendirilmediği müddetçe halk; yalnızca oy vererek yönetim içinde görece pasif bir konuma gelmiştir. Bu durum ise katılımcı demokrasi fikrinin güç kazanmasına ve vatandaşın siyasi alanda daha aktif bir rol almasını sağlayacak, ona yeni sorumluluklar yükleyecek daha sistemli bir yönetim anlayışının geliştirilmesini gerekli hale getirmiştir (Yaman ve Küçükşen, 2018: 251).

Literatür tarandığında katılımın demokrasinin temel kavramlarından biri olduğu sonucuna varılmaktadır. Oy verme işleminin ardından yurttaşın misyonu sonra ermez. Bireyin kendini 
yönetecek kişi ve kuruluşların uygulamalarında, karar verme süreçlerinde söz sahibi olması demokrasinin önemli bir ayağını oluşturmaktadır (Demir, 2010: 602). Bu anlayışa göre vatandaşların çeşitli örgütler aracılığı ile kamu düzeyinde alınan idari ve siyasi kararları etkileyebilmesi ve değiştirebilmesi demokrasinin esaslarından biridir.

Öte ayandan katılımın, süreklilik, geniş kapsamlı etki, gönüllülük esası, bireysel olmama, toplum çıkarlarını gözeten geniş görüşlülük gibi özellikleri bulunmaktadır (Kent Şurası, 2009: 21). Ayrıca demokratik ilkelere uygun olarak katılım süreçlerinde vatandaşların din, dil, ırk vb. gibi konularda ayrım gözetmeksizin eşit haklara sahip olması da katılımın temel özelliklerinden biridir (Pektaş ve Akın, 2010: 45).

Katılımın gerçekleşmesi ile toplumsal hedefler; vatandaş ve yöneticinin bir arada karar alması ile belirlenmektedir. Yönetilen bireylerin yöneticiler üzerinde daha aktif bir etkiye sahip olmas1 yolu ile demokrasinin işlevselliğinin arttırılması katılımın geliştirilmesiyle mümkün hale gelmektedir (Oruç ve Bayrakcı, 2018: 466).

Demokratik katılımın gerçekleştirilmesi için geçmişten günümüze farklı yöntemlere başvurulmuştur. Geleneksel katılım yöntemlerinin yanı sıra gelişen dünyanın getirileri olarak ortaya yeni yöntemler de çıkarılmış. Katılımın en klasik yollarından olan yerel seçimler, bahsi geçen geleneksel yöntemlerin başında gelir. Bunun yanı sıra referandumlar da yurttaş katılımının önemli bir unsuru olarak karşımıza çıkmaktadır (Yaman ve Küçükşen, 2018: 252). Geleneksel yöntemlerin dışında devlet ve demokrasi fikirlerinin değişime uğraması sürecinde ortaya çıkan başka birtakım katılım yöntemi ile karşılaşmak da mümkündür. Bu yöntemlere örnek olarak ise halk meclisleri, yurttaş kurulları, kent konseyleri, ihtisas komisyonları ve meclis toplantılarına katılma hakkı gösterilebilir. Ayrıca sivil toplum kuruluşları siyasal katılımın en önemli kanallarından biri olarak sayılmaktadır (Yaman ve Küçükşen, 2018: 253).

Katılım, ulusal ve yerel düzeyde gerçekleştirilebilen bir iş olarak devletin bütün kurumlarını ilgilendiren bir kavramdır. Özellikle yerel yönetimler bireylerin siyasi katılım gösterebilmesi için en uygun ortam olarak görülmektedir (Oruç ve Bayrakc1, 2018: 468). Yapılan çalışmalar, katılımcı anlayışın benimsendiği yerel yönetimlerde çalışanların ve bölge halkının motivasyon düzeylerinin daha yüksek olduğunu göstermektedir. Vatandaşların siyasi katılım sağlayabilecekleri ilk birim olarak yerel yönetimlerin katılımcı demokrasi konusundaki önemi de bu şekilde ortaya çıkmaktadır.

Dolayısıyla katılım, demokrasinin en önemli ilkelerinden biri olarak karşımıza çıkmaktadır. Bu nedenle katılımcı demokraside halkın siyasal katılımının sağlanması için çeşitli kanallar oluşturulmaktadır. Bu kanallar yerelden merkeze doğru bir sıra ile ilerlemektedir. Yerel yönetimler, katılımın üst düzeye çıkarılması için ilk basamak olup halkın en rahat ulaşabildiği siyasi ve idari birimlerdir. Bu sayede halkın yönetim konusunda etkin bir role sahip olması ve yönetilenlerin devlet yönetiminde bir karar mekanizması haline gelmesi olası hale gelmektedir.

\section{Yerel Yönetimlerde Katılımcı Demokrasi Anlayışı}

Yerel katılım yöntemleri arasında yer alan katılımcı demokrasi; vatandaşların oy verme hakkını kullanmasının ardından da çeşitli yollar ile siyasi karar alma süreçlerine ve uygulamalara dâhil olması anlamına gelen bir kavramdır. Katılımc1 demokrasi uygulamaları klasik demokrasi uygulamalarının idealleştirilmesini hedefleyen bir düşünce olarak ortaya çıkmıştır. Değişen 
dünya düzeninin bir sonucu olarak etkisiz kalmaya başlayan temsili demokrasiye bir alternatif oluşturan katılımcı demokrasi; vatandaşların yöneticilerin verdiği kararlar üzerinde etkili olabilmesi için uygun ortam yaratarak demokratik uygulamaların güç kazanmasına yardımcı olmaktadir (Yaman, 2018: 82).

Katılımc1 demokrasinin amac1; demokratik yapıları en üst düzeyde katılımcı hale getirmek ve böylece çok da sağlıklı işleyen, halkın bire bir olarak yönetimin içinde olmasını sağlayacak bir ortam yaratmaktır. Böyle bir ortamda yurttaşların sorunlarını yöneticiler karşısında rahatça dile getirmesi, gereğini talep etmesi, süreci değiştirmek hatta durdurmak gibi olanaklara sahip olması mümkün hale gelmektedir. Bu sayede demokratik yapılar beklendiği üzere halkın etkin olduğu bir görünüme daha da yaklaşmaktadır (Çal, 2007: 610).

Toplumsal bir beklentinin, bir eksikliğin karşılanması ve tamamen kamu yararının göz önüne alınarak yapılması bakımından devletin en temel görevlerinden birinin kamu hizmetlerini gerçekleştirmek olduğu söylenebilir. Yerel yönetimler ise; kamu hizmeti sağlanması konusunda kamu idaresinin en temel birimleri olarak karşımıza çıkmaktadır (Bayrakcı ve Kahraman, 2017: 310). Öte yandan yerel yönetimler, demokratik sistemlerde kamu hizmetlerinin halka ulaştırılmasını sağlamak ile birlikte demokrasi faaliyetlerinin daha sağlıklı bir biçimde yürütülmesi amacını da taşımaktadır. Zira yerel siyasetin niteliği ekonomik, yönetsel, siyasal ve demokratik boyutlarda halkın yaşam kalitesinin arttırılmasıdır (Çukurçayır, 2008: 77). Bulunduğu bölgenin halkı ile bire bir iletişim içinde olma özelliğine sahip olan bu yönetim mekanizması, katılımın gerçekleşmesi ve vatandaşların kararlara dâhil olması noktasında oldukça geniş bir etki alanına sahiptir. Aynı zamanda siyasal katılım, yerel ve merkezi yönetimler arasında bir bütünleştirici unsur olarak da görülmektedir (Çukurçayır, 2008: 78).

Katılımc1 demokrasinin hâkim olduğu bir yerel yönetimde vatandaşların kolayca ulaşabilecekleri ve kendilerini ilgilendiren bütün yönetsel süreçler hakkında söz sahibi olacakları, çeşitli araçlar ve yollar bulunmaktadır. Zira halkın etkin olarak katılım gösterdiği yerel yönetimlerin işleyişleri daha sağliklı bir biçimde olmakta ve demokrasilerin gelişmesine zemin hazırlamaktadır. Bu anlamda demokratik yerel yönetimlerin ilk ayağı yöneticilerin halkoyları ile seçilmesidir. Ardından halk meclisleri, sivil toplum örgütleri, halka açık meclis toplantıları veya kent konseyleri gibi yollarla vatandaşların bire bir katılım sağlayacağ kanalların açılması gerekmektedir (Yaman ve Küçükşen, 2018: 254).

$\mathrm{Bu}$ kanallar, yerel yönetimlerde başlayarak ulusal düzeye ulaşan ve esnekliğin ön planda tutulduğu katılımcı demokrasi uygulamalardır. Öyle ki yerel yönetimler halkın doğrudan siyasi katılım sağlayabileceği mahalle meclisleri ya da halka açık toplantılar gibi yollarla vatandaşları süreçlere dâhil edebilmektedir (Sakınç ve Bursalıoğlu, 2014: 37). Ayrıca değişen teknoloji ile entegre edilmiş bir yönetim biçiminin benimsenmesi de güçlü yerel yönetimlerin ortaya çıkması için önem taşımaktadır. Kaldı ki çoğulculuk, siyasi katılım, demokratiklik gibi konularda gelişmiş bir toplumda demokratik bir yerel yönetim anlayışı yer edinebilmektedir. Buradan hareketle demokrasi anlayışının ulusal düzeyde etkili olmasının yerel düzeyde gelişmenin de bir etkeni olduğunu söylemek yanlış olmayacaktır. Bir başka açıdan ise yerel siyaset de; sivil kültürün ve demokrasinin güçlenme alanı olarak görüldüğünden kamuoyu oluşturma, doğrudan katılım, itiraz ve protesto gibi yollarla ulusal demokrasiye katkıda bulunan bir unsur olma özelliği taşımaktadır (Tekeli, 2004: 55). 
$\mathrm{Bu}$ açıklamalardan hareketle yerel yönetimlerin demokratik ve siyasi katılımın güçlenmesi doğrultusunda çalışmalar yürütmesinin bir gereklilik olduğu sonucuna ulaş1labilmektedir. Mahalli idare kurumlarının yanı sıra katılım konusunda bilinçli ve istekli vatandaşların bulunması da, yerel siyasette demokratikleşme ve gelişim sürecini hızlandıracak bir unsurdur (Dursun, 2008: 79). Yerel yönetimlerin halk ile bütünleşik ve şeffaf bir politika izlemesi yurttaşların katılım konusunda eğitimli ve bilinçli hale getirilmesi de bu noktada ön plana çıkan etmenler arasında yer almaktadır.

Dolayısıyla yerel siyaset, demokrasi işleyişinin temel basamaklarından biri olarak katılım ve demokrasi açısından önemi inkâr edilemez bir yere sahiptir. Yurttaşların aktif katılım gösterebilmeleri, yönetime dâhil olabilmeleri, yürütülen devlet politikalarının uygulamalarında yer alabilmeleri, itiraz ve protesto faaliyetlerinde bulunabilmeleri için yerel yönetimler işlevsel demokratik kurumlar olarak varlığını sürdürmektedir.

\section{Belediyelerde Katılımcı Demokrasiye Katkı Sağlayan Yöntemler}

Katılımcı demokrasinin yerel düzeyde uygulayıcısı olarak ifade edilebilecek belediyelerde halkın yönetime dahil olması için birtakım yöntemlere başvurulmaktadır. Bu yöntemler katılım konusunda halkın bilgi sahibi olması ve kendilerini ilgilendiren konularda görüş, eleştiri ve projelerini yöneticilere iletebilmesi açısından önem taşımaktadır. Bütün vatandaşların herhangi bir ayrım gözetmeksizin katılım göstermesi için geliştirilmiş bu yöntemlerden günümüzde etkili olarak kullanılmakta olan halk toplantısı, meclis toplantılarına katılım, kent konseyleri ve yurttaş kurullarıdır.

Temelinde bilgilendirme amacı bulunan halk meclisleri yurttaşların katılım oranlarını arttırarak daha güçlü yerel yönetim mekanizmaları ortaya çıkarmayı hedeflemektedir (Görün, 2006: 92). Ayrıca halk toplantıları sayesinde yerel halk kendilerini yakından ilgilendiren konularla ilgili olarak fikir beyan edebilme ve belediyenin alacağı kararlarda etkin rol oynayabilme olanağına sahip olmaktadır. Öte yandan yerel yönetimlerde halk temsilinin yalnızca oy vermek ile sınırlandırılmasının demokratik açıdan yetersiz kalması nedeni katılımcı anlayışın bir sonucu olarak vatandaşların meclis toplantılarına katılım hakkı ile ortaya çıkmaktadır. Halkın belediye meclis toplantılarına katılımı yönetim konusunda bilgi sahibi edilmeleri ve uygulamaları etkileyecek görüşlerini yönetime iletmeleri için uygun bir ortam yaratmaktadır (Görün, 2006: 94). Meclis toplantılarına katılma yönteminin; yerel düzeyde vatandaşların şikâyet, dilek ve beklentilerini beyan edebilecekleri; demokrasinin temel getirileri olan hak ve özgürlükleri doğrultusunda yönetime yasal yollardan dahil olabilecekleri bir yöntem olduğunu söylemek mümkündür.

Kent konseyi ise, halk toplantıları ile benzerlik göstermesine karşın konseylerde halkın temsili noktasında etkin aktörün sivil toplum kuruluşları olması nedeniyle halk toplantılarından ayrılmaktadır. Küreselleşmenin bir getirisi olarak artan sivil toplum hareketlerinin yerel düzeyde söz hakkına eriştiği kent konseylerinde halkın istek ve şikâyetlerinin yöneticilere aktarılması ve projelerinin değerlendirilmesi yolu ile etkin bir katılım ortamı ortaya çıkmaktadır (Yaman ve Küçükşen, 2018: 256).

Belediyelerde katılımı gerçekleştirmek, arttırmak ve geliştirmek için uygulanan bir diğer yöntem ise yurttaş kurullarının hayata geçirilmesidir. Yurttaş kurulları özellikle toplumda ihmal 
görmekte olan grupların yerel katılımlarını arttırmak amacı ile oluşturulan katılım organlarıdır. Yardıma muhtaç kişiler, engelliler, yabancı uyruklu vatandaşlar, kadınlar ve çocuklar yurttaş kurullarının katılımda etkili hale getirmeyi amaçladığı gruplar arasında yer almaktadır (Görün, 2006: 95). Bahsi geçen gruplar arasından seçilen temsilcilerin katılımı ile gerçekleştirilen yurttaş kurulları; daha çok danışmanlık işlevi görmektedir. Bununla birlikte yapılan çalışmaların karar alma süreçlerini etkilediği de uygulamalarda görülmektedir.

Yurttaş kurulları yolu ile toplumda sesini duyurmakta zorluk çeken bireylerin yöneticilere ve kamuoyuna sorunlarını ve dileklerini iletebilmeleri söz konusu olmaktadır. Yasa önünde eşitlik ilkesi gereğince katılımcı demokrasilerde herkesin yönetim sürecine dâhil olması beklendiğinden yurttaş kurulları siyasi katılımın geliştirilmesi için önem taşıyan bir organ olma özelliği göstermektedir.

Bahsi geçen katılım yöntemlerinin etkili bir biçimde kullanılması, mahalli yönetimlerin etki alanını arttırdığı gibi hizmet kalitesinin artması ve halkın kamu hizmetlerinden tatmin olması gibi sonuçları beraberinde getirecektir. Toplumun bütün kesimlerinden insanın yönetim süreçlerinde etkili olabilmesi aynı zamanda yerel demokrasinin de güç kazanması için önemli bir unsurdur. Katılımın üst düzeyde gerçekleştiği yönetimlerde yerel düzeyde başlayan demokratik güç ulusal boyutlara da ulaşarak genişlemektedir.

Demokrasinin etkin bir biçimde uygulandığı devletlerde yerel katılım yöntemlerinin geliştirilmesi ve arttırılması beklenmekte olup sürecin yapılan uygulamalarla desteklenmesi de önem taşımaktadır. Aksi takdirde halkın yönetimin halkın beklentilerini karşılamayan ve kamu hizmeti tatmininin gerçekleşmediği bir devlet düzeninin ortaya çıkması gibi sorunlar ile karşılaşmak mümkündür.

\section{Kadıköy Belediyesi Katılımcı Demokrasi Uygulamaları}

Katılım kavramının demokrasiler için önemi yapılan çalışmalarda sıkça vurgulanan bir durumdur. Son yıllarda demokrasilerin temel ilkeleri doğrultusunda katılımın arttırılması için çeşitli yollara başvurulduğu da görülmektedir. Bu yolların kuramsal olarak hangi temellere dayandığını anlayabilmek için yerel katılım yöntemlerinin somut örnekler üzerinden incelenmesi faydalı olacaktır. Açıklanan nedenle Kadıköy Belediyesi özelinde demokrasi uygulamaları ve katılımın gerçekleştirilmesi için kullanılan yöntemlerden bahsedilecektir.

Kadıköy, İstanbul'un Anadolu Yakası'nda yer alan ilçesidir. Kocaeli Yarımadası'nın güneybatı kesiminde bulunan Kadıköy, batı ve güneyde Marmara Denizi, kuzeyde Üsküdar, kuzeydoğuda Ataşehir ve doğuda Maltepe ilçeleriyle çevrilidir.

Kadıköy'de beraber yaşayan vatandaşların, ilçedeki gereksinimlerinin karşılanabilmesi için oluşturulan ve yerel demokrasinin en iyi işlediği yer olan Belediye bünyesinde yapılan katılımcı demokrasi uygulamaları, vatandaşların yöneticilerin verdiği kararlar üzerinde etkili olabilmesi için uygun ortam yaratarak demokratik uygulamaların güç kazanmasına yardımcı olmaktadır (Yaman, 2018: 122).

Kadıköy Belediyesi, Dünya Sağlık Örgütü Sağlıklı Kentler Projesi felsefesinde yerini ve ifadesini bulan halk katılımı, kentsel yoksulluk, kentsel yönetim, kentsel planlamaya ilişkin strateji ve politikalar geliştirmek, Kadıköy'ün sorunlarının tespiti ve çözümünde kent 
ortaklarıyla birlikte hareket edebilmek konusunda sorumlu yerel yönetim anlayışı ile bu hareket içinde yerini almak için, Kadıköy Kent Konseyi'ni Kadıköy Belediye Meclisi'nin 11.02.2004 gün ve 2004/6 sayılı kararı ile 17.05.2004 tarihinde kurmuştur (Kadıköy Belediyesi 2006-2009 Stratejik Plan). Kadıköy Kent Konseyi'nin çalışma grupları ise; Engelli Meclisi, Gençlik Meclisi, Kadın Meclisi, Çocuk Meclisi, Kıdemli Hemşehriler Meclisidir.

Kadıköy Kent Konseyi'nin çalışma gruplarından Gençlik Meclisi, yerel ve ulusal demokratikleşme sürecinde, gençlerin düşüncelerini açıkça söyleyebilmelerini, çözüm üretebilmelerini, karar alma mekanizmalarına aktif katılımlarını sağlayan ve kendi sorunlarına sahip çıkmalarını özendiren gönüllülük temelinde, demokratik bir oluşumdur. Gençlerin, meclis çatısı altında yaratılan uzlaşma ortamı içerisinde, dil, din, ırk, kültür, sınıf, eğitim ve cinsiyet farkı gözetmeksizin kentin sürdürülebilir gelişmesinin temelini oluşturacak politikaların yaratılmasında ve öncelikli sorunların belirlenerek bunların çözüm önerilerinin üretilmesine ve uygulanmasına katkıda bulunmalarını sağlar (Gençlik Meclisi Çalışma Yönergesi m.4).

Kadıköy Belediyesi Kadın Meclisi; katılımcılık, sürdürebilirlik, yaşanabilirlik, kentsel hakların geliştirilmesi, hoşgörü ve uzlaşma ilkeleri 1şığında, düşüncelerini açıkça söyleyebilme, çözüm üretebilme, karar alabilme ve uygulayabilme mekanizmaları geliştirmeyi sağlayan ve kendi sorunlarına sahip çıkmalarını özendiren demokratik bir platformdur (Kadın Meclisi Çalışma Yönergesi m.5).

Kadıköy Kent Konseyi ilkeleri doğrultusunda faaliyet gösteren bir diğer platform ise, çocukların kent yönetimine aktif katılımda bulunmaları için çalışmaların gerçekleştirildiği Çocuk Meclisi'dir (Çocuk Meclisi Çalışma Yönergesi m.5). Bu meclis, Kadıköylü çocukların kent yönetimine aktif olarak katılmalarını, kendileri ve kentle ilgili sorunlarının çözümünde rol almalarını sağlamak, çocukların çevre duyarlılı̆̆ını artırmak, Kadıköy çocuklarını, kent düzeyinde, ulusal ve uluslararası düzeyde temsil etmek, çocukların kentlilik bilincini geliştirmek, çocukların insan hak ve özgürlüklerine saygılı, araştıran, üreten, girişimci bireyler olmalarını sağlamak, çocukların ortaklık bilinci içinde, dayanışma ve paylaşma duygularının gelişmesini sağlamak gibi amaçlar çerçevesinde faaliyet göstermektedir (Çocuk Meclisi Çalışma Yönergesi m.6).

Kıdemli Yurttaşlar Meclisi ise; Kadıköy Kent Konseyi ilkeleri doğrultusunda, kıdemli yurttaşların kent yönetimine aktif katılımda bulunmaları için çalışmaların gerçekleştirildiği bir platformdur. Kent içinde yaşayan kıdemli yurttaşların din, dil, ırk, kültür, sınıf, eğitim ve düşünce farkı gözetmeksizin temsil edilmesini, özgür ve doğrudan katılımı sağlar (Kıdemli Yurttaşlar Meclisi Çalışma Yönergesi m.5).

Bir diğer çalışma platformu olan Kadıköy Belediyesi Engelliler Meclisi’nin, engellilerinin insan hak ve özgürlüklerinden, tam ve eşit biçimde yararlanmalarını sağlamak, engellileri ve engelliliği hedef alan, ayrımcı kural, uygulama, davranış, alışkanlık ve önyargılarının ortadan kaldırılmasına çalışmak, hak ve imkanlar ile, arzu edilen hedefe erişmenin önünde engel oluşturan, düzenlemelerin, engelliler bakımından ihtiyaca cevap verecek hale getirilmesi ile, fırsat eşitliğini oluşturmak, uygulama ve düzenlemeler bakımından, engelli bireylerin onurunun kırılmasına ve engelliliğin çıkar temininin bir aracı haline getirilmesine yönelik istismarcı anlayışlarla mücadele etmek, Kadıköy'ün erişilebilirlik düzeyini arttırmak, bireysel çabalarla erişilemeyecek teknoloji ve hizmetlerin gereği planlama ve sunumun yapılmasına, bu bağlamda 
ihtiyaç duyulacak olan merkez ve tesislerin açılmasına çalışmak, Kadıköy'deki engellilerle ilgili çalışma yapan taraflar arasında eşgüdümü sağlamak gibi amaçları vardır (Engelliler Meclisi Çalışma Yönergesi m.5).

\section{SONUÇ}

İzah edildiği üzere, yönetilen bireylerin yöneticiler üzerinde daha aktif bir etkiye sahip olması yolu ile demokrasinin işlevselliğinin arttırılması katılımın geliştirilmesiyle mümkün hale gelmektedir. $\mathrm{Bu}$ nedenle demokratik katılımın gerçekleştirilmesi için geçmişten günümüze farklı yöntemlere başvurulmuş, geleneksel katılım yöntemlerinin yanı sıra gelişen dünyanın getirileri olarak ortaya yeni kurumlar ortaya çıkarılmıştır. Geleneksel anlayıştan yeni kamu yönetimi anlayışına geçişin bir sonucu olarak görülebilecek katılımcı demokrasi uygulamaları bunlardan bazılarıdır. Özellikle yerel yönetimler düzeyinde sıklıkla görülen halk meclisleri, yurttaş kurulları, kent konseyleri, ihtisas komisyonları ve meclis toplantıları gibi uygulamalar, kamu hizmetlerinden yararlanan halkı yönetimin ve yerel hizmetin merkezine çekmesi nedeniyle ideal demokrasi anlayışına yaklaşma yönünde olumlu bir gelişmelerdir.

Türkiye'de de yerel yönetimler bünyesinde faaliyet gösteren kent konseyleri ve meclisleri ara kurum olarak kendini göstermiş ve bu yönde bir işlev yüklenmiştir. Katılımcı demokrasi anlayışının tabana yayılmasını sağlamak amacıyla son derece önemli bir görev üstlenen bu meclisler, halkı yönetimin ve yerel hizmetin merkezine çekmektedir. Halkın bilgi sahibi olması ve kendilerini ilgilendiren konularda görüş, eleştiri ve projelerini yöneticilere iletebilmesi açısından önem taşıyan ve kuşkusuz en önemli yerel yönetim biçimi olan belediyelerde, kent konseyi, gençlik, kadın, çocuk, kıdemli yurttaş, engelli meclisleri gibi kurumlar aracılığıyla yönetime dâhil olması günümüzde katılımcı demokrasi uygulamalarının etkili olarak kullanıldığını göstermektedir.

$\mathrm{Bu}$ kapsamda, örnek inceleme konusu olarak seçilen Kadıköy Belediyesi'nde, İlçe'nin sorunlarının tespiti ve çözümünde kent ortaklarıyla birlikte hareket edebilmek anlayışı ile Kadıköy Kent Konseyi, gençlerin meclis çatısı altında yaratılan uzlaşma ortamı içerisinde, dil, din, ırk, kültür, sınıf, eğitim ve cinsiyet farkı gözetmeksizin kentin sürdürülebilir gelişmesinin temelini oluşturacak politikaların yaratılmasına katkıda bulunmaları için Kadıköy Gençlik Meclisi, kent içinde yaşayan kadınların, ayrım gözetilmeksizin temsil edilmesini, özgür ve doğrudan katılımını sağlamak amacıyla Kadıköy Kadın Meclisi, çocukların kent yönetimine aktif katılımda bulunmaları için çalışmaların gerçekleştirildiği bir platform olan Kadıköy Çocuk Meclisi, Kent Konseyi ilkeleri doğrultusunda, kıdemli yurttaşların kent yönetimine aktif katılımda bulunmalarını sağlamak için Kıdemli Yurttaşlar Meclisi, engellilerinin insan hak ve özgürlüklerinden, tam ve eşit biçimde yararlanmalarını sağlamak amacıyla Kadıköy Engelli Meclisi kurulmuş ve faaliyetlerine devam etmektedir.

Özetle bireyin mahallede beraber yaşaması sonucu oluşan gereksinimlerin karşılanabilmesi için oluşturulan ve yerel demokrasinin en iyi işlediği yerler olan belediyelerin işlevlerinin, halkın siyasi, idari, politik, teknolojik, sosyo-kültürel, ekonomik değişimlerine bağlı olarak sürekli değişime uğradığı ve sorunlarının tespiti ile çözümünde kent ortaklarıyla birlikte hareket edebilmek anlayışı benimsendiği, Kadıköy Belediyesi özelinde de görülmektedir. 


\section{KAYNAKLAR}

Akdoğan, Y. (2008). Yerel Siyaset-Kavramlar. Yerel Demokrasi Ve Yerel Siyaset. Ed. Şentük, Hulusi. Yerel Siyaset. Okutan Yayınları, İstanbul, 9-15.

Bayrakcı, E.,\& Kahraman, S. (2017). Yeni Kamu Hizmeti Anlayışı Ve Belediyelerde Özelleştirme. Selçuk Üniversitesi Sosyal Bilimler Enstitüsü Dergisi, (37), 299-315.

Çal, S. (2007). Kamu Hizmeti: Bir Tanım Denemesi. Gazi Üniversitesi Hukuk Fakültesi Dergisi, 11(1-2), 599-655.

Çukurçayır, M. A. (2008). Yerel Demokrasi Ve Yerel Siyaset. Ed. Şentük, Hulusi. Yerel Siyaset. Okutan Yayınları, İstanbul.

Demir, N. (2010). Demokrasinin Temel İlkeleri Ve Modern Demokrasi Kuramları. Ege Academic Review, 10(2), 597-611.

Dursun, D. (2008). Demokratik Siyasal Kültürün Gelişmesinde Yerel Yönetimler. Yerel demokrasi ve yerel siyaset. Ed. Şentük, H. Yerel Siyaset. Okutan Yayınları, İstanbul. $77-86$.

Eryılmaz, B. (2009). Kamu Yönetimi, Okutman Yayıncılık, Ankara.

Görün, M. (2006). Yerel Demokrasi ve Katılım: İzmir, Konya ve Ağrı İl Genel Meclis Üyeleri Üzerinde Bir Araştırma.Yönetim Bilimleri Dergisi 4(2), 159-183.

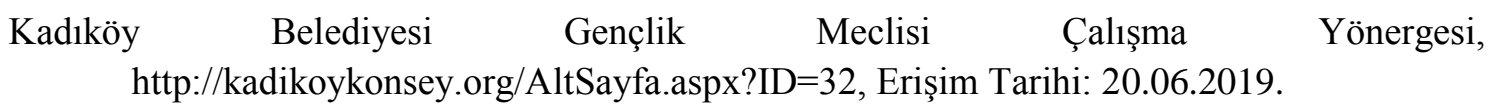

Kadıköy Belediyesi Kadın Meclisi Çalışma Yönergesi, http://kadikoykonsey.org/AltSayfa.aspx?ID=32, Erişim Tarihi: 20.06.2019.

Kadıköy Belediyesi Çocuk Meclisi Çalışma Yönergesi, http://kadikoykonsey.org/AltSayfa.aspx?ID=32, Erişim Tarihi: 20.06.2019.

Kadıköy Belediyesi Kıdemli Yurttaşlar Meclisi Çalışma Yönergesi, http://kadikoykonsey.org/AltSayfa.aspx?ID=32, Erişim Tarihi: 20.06.2019.

Kadıköy Belediyesi Engelliler Meclisi Çalışma Yönergesi, http://kadikoykonsey.org/AltSayfa.aspx?ID=32, Erişim Tarihi: 20.06.2019.

Kaypak, Ş. (2012). Yerel Yönetimlerde Katılımcı/Müzakereci Demokrasi Sürecinde Sivil Toplum Kuruluşlarının Önemi. Uluslararası Yönetim İktisat ve İşletme Dergisi, 8(17), 171-196.

Kent Şurası. (2009). Kent, Yoksulluk, Göç ve Sosyal Politikalar. T.C. Bayındırlık ve İskân Bakanlığı, Ankara.

Oruç, T.,\& Bayrakçı, E. (2013). Yerel Siyasette Temsil Ve Katılım: Kadın aktörler. MANAS Sosyal Araştırmalar Dergisi, 7(2), 463-480.

Pustu, Y. (2005). Yerel Yönetimler Ve Demokrasi.Sayıştay Dergisi, 57, 121-134. 
Sakınç, S.,Bursalığlu, S., (2014). Bütçelemede demokratik bir değişim: katılımcı bütçeleme. Electronic Journal of VocationalColleges,.http://www.ejovoc.org/makaleler/may_2014/pdf/01.pdf. Erişim Tarihi: 20.06.2019.

Tekeli, İ. (2004). Katılımcı Demokrasi, Sivil Ağlar Ve Sivil Toplum Kuruluşları, 15. STK Sempozyumu, 18-19 Haziran 2004, İstanbul.

Yaman, F. (2018). Katılımcı Demokrasi: Kapsam ve Unsurlar. Trakya Üniversitesi İktisadi ve İdari Bilimler Fakültesi Dergisi, 6(2), 136-160.

Yaman, M.,\& Küçükşen, M. (2018). Yerel Yönetimlerin Demokratikleşmesi Açısından Yerel Katılımın İncelenmesi. Dumlupınar Üniversitesi Sosyal Bilimler Dergisi, (55), 247-259.

Yayla, Y. (1990). İdare Hukuku. Filiz Kitabevi, İstanbul.

Kadıöy Belediyesi 2006-2009 Stratejik https://anlat.kadikoy.bel.tr/kbpanel/Uploads/Files/2006-2009\%20Stratejik_Plani.pdf, Erişim Tarihi: 20.06.2019. 